\title{
A Patient with Symmetrical Polyarthritis. The Value of Conventional Radiography for a Correct Diagnosis
}

\author{
Alexandros A. Drosos (D) - Eleftherios Pelechas (D) P Paraskevi V. Voulgari (i)
}

Received: December 12, 2021 / Accepted: January 20, 2022 / Published online: February 3, 2022

(C) The Author(s) 2022

\begin{abstract}
Purpose of Review: Among the imaging modalities for the investigation of articular damage of patients with peripheral inflammatory arthropathies, conventional radiography (CR) is the mostly used. Other imaging modalities such as the musculoskeletal ultrasonography, magnetic resonance imaging, and dualenergy computed tomography scans are often used depending on a patient's clinical needs.

Recent Findings: With the publication of new classification criteria for rheumatoid arthritis (RA), spondyloarthropathies, polymyalgia rheumatica, and others, many physicians are not using any of the above imaging techniques because they believe that by relying only on the classification criteria of a disease the diagnosis can be an easy task.
\end{abstract}

Summary: We present a patient with peripheral symmetrical polyarthritis involving the

\footnotetext{
A. A. Drosos ( $\square)$ · E. Pelechas · P. V. Voulgari Department of Internal Medicine, Medical School, Rheumatology Clinic, University of Ioannina, 45110 Ioannina, Greece e-mail: adrosos@uoi.gr

URL: https://www.rheumatology.gr

E. Pelechas

e-mail: pelechas@doctors.org.uk

P. V. Voulgari

e-mail: pvoulgar@uoi.gr
}

small joints of the hands, diagnosed and treated as RA and we discuss the role of imaging, especially the use of CR as an initial screening tool for the evaluation of the articular manifestations and joint damage, and its further usefulness in order to reach a definitive correct diagnosis.

Keywords: Peripheral arthropathy; RA; CPPD; Imaging; Conventional radiography

\section{Summary Points}

Conventional radiography is a helpful imaging technique and should be used appropriately.

Calcium pyrophosphate deposition disease is a common clinical entity and should be sought in patients with presumed hand arthritis.

Hand and wrist radiographs should be carried out in patients with a clinical picture of inflammatory arthritis.

There is no standard treatment for calcium pyrophosphate deposition disease, but colchicine and methotrexate have been proven to be helpful in some cases. 


\section{INTRODUCTION}

Conventional radiography (CS) is the classical diagnostic technique used mostly for the evaluation of the articular manifestations and joint damage in patients with signs and symptoms of inflammatory arthropathy (IA) [1, 2]. However, nowadays, with the advent of musculoskeletal ultrasonography (MSUS), the use of magnetic resonance imaging (MRI), and dualenergy computed tomography (CT) scan, the use of CR for patients with peripheral IA is limited [3-7]. The above techniques, especially MSUS and MRI, are considered far better tools than CR because they are able to visualize not only early changes of a disease (i.e., early bone erosions), but also soft tissue findings like synovitis as well as tendon and ligament damage. On the other hand, both techniques are time-consuming, require highly trained personnel, radiologists and/or rheumatologists, and are operator- and machine-dependent. Additionally, with the publication of new classification criteria for rheumatoid arthritis (RA) [8], spondyloarthritis (SpA) [9], polymyalgia rheumatica [10], and gout [11], many physicians are not using any of the aforementioned imaging modalities in order to help them reach to a final diagnosis because they believe that by relying solely on the application of the classification criteria of a disease, the presumptive diagnosis is obvious, which in several cases may prove to be the wrong choice. Thus, the questions which arise here are: is CR still an appropriate screening tool for assessing IA? Why should once choose $\mathrm{CR}$ and what is its usefulness? To this end, we present a patient with symmetrical polyarthritis affecting the small joints of the hands and wrists, diagnosed as having RA, and we will try to give answers to these questions. This study was performed in accordance with the Helsinki Declaration of 1964 and its later amendments. All presented material is published after written consent of the patients, although sensitive data and personal details are not included in the publication.

\section{CASE PRESENTATION}

A 60-year-old woman presented with pain and stiffness of the small joints of the hands bilaterally, starting 2 months previously. She received both analgesics and non-steroidal antiinflammatory drugs (NSAIDs) without any significant improvement. She then visited a specialist rheumatologist who found swelling and tenderness affecting the metacarpophalangeal (MCPs) and proximal interphalangeal (PIPs) joints as well as the wrists in a symmetrical manner. Past medical and family history were unremarkable. She denied psoriasis, oral ulcers, urethritis, diarrhea, Raynaud's phenomenon, photosensitivity, and thyroid disease. Laboratory tests revealed a high erythrocyte sedimentation rate (ESR) of $68 \mathrm{~mm} / \mathrm{h}$, and a C-reactive protein (CRP) of $20 \mathrm{mg} / \mathrm{dl}$ (normal values $<6$ ), while rheumatoid factor (RF), anticitrullinated protein antibodies (ACPA), and antinuclear antibodies (ANA) were all negative. The rest of the serological tests also came back negative. Thus, according to the 2010 American College of Rheumatology (ACR) and the European League Against Rheumatism (EULAR) Classification criteria for RA, she had a score of $7 / 10$ for definite RA [8]. To this end, she started treatment with methotrexate (MTX) $15 \mathrm{mg} /$ week, plus prednisone $10 \mathrm{mg} /$ day. Indeed, after 2 months she felt very well, without pain, while the stiffness and swelling of her joints had disappeared. Additionally, the ESR and CRP levels decreased to normal values. The dose of prednisone was tapered, and 3 months later was discontinued, while she carried on with MTX. One year after the initiation of treatment, she was in complete clinical remission with normal acute phase reactants. At this point, the patient discussed with her doctor the possibility of discontinuing MTX therapy, but he advised her that RA is a chronic disease and needs long-term treatment and follow-up. After that, the patient visited another rheumatologist, who after a detailed clinical and laboratory investigation revealed no signs of arthritis and he ordered hand and wrist X-rays. The radiographs showed soft tissue and cartilage calcifications affecting mostly the PIPs, MCPs, as well as the distal interphalangeal 
joints (DIPs) and the first carpometacarpal joint of the right hand, a picture compatible with calcium pyrophosphate (CPP) deposition disease (CPPD) (Fig. 1). MTX was discontinued, and 12 months later the patient continued to feel well without any additional treatment. Before discussing our case let's review in brief how to evaluate and interpret CR of hand and wrists.

\section{EVALUATION \\ AND INTERPRETATION OF HAND AND WRIST RADIOGRAPHS}

$\mathrm{CR}$ of the hand and wrist provides important information as a screening tool in patients with peripheral arthropathy. The posteroanterior and the Nørgaard projection (which is an anteroposterior oblique view) are used for a detailed radiographic evaluation. Both views can give information about any cortical bone changes. For an accurate diagnosis, one must observe not only the radiographic changes occurring in a specific joint, but also the distribution of these changes within the hands and wrists. Soft tissue swelling, subluxations, changes in bone mineralization, calcifications, bone proliferation, joint space narrowing, and erosions are the radiographic changes occurring around a specific joint and need to be evaluated $[1,2]$.

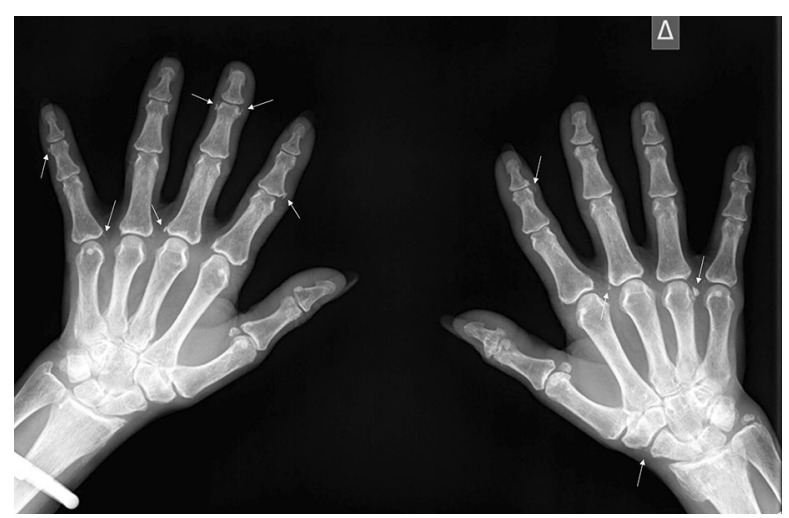

Fig. 1 Calcium pyrophosphate deposition disease: soft tissue and cartilage calcifications affecting the PIPs, MCPs, DIPs, and the 1 st CMC of the right hand in a 60-year-old female with symmetrical polyarthritis

\section{Soft Tissue Swelling}

Symmetrical swelling can be easily evaluated around the interphalangeal joints (proximal, distal), and wrists. This type of swelling is not characteristic of a specific IA, but is most common in RA patients. Asymmetrical swelling may not be an actual soft tissue swelling, but rather soft tissue asymmetry due to the bone enlargement from an osteophyte or due to subluxations. An asymmetric swelling can be seen in osteoarthritis (OA), and erosive OA. Swellings around the DIPs are named Heberden's nodes, while those around the PIPs are called Bouchard's nodes. Diffuse fusiform swelling affecting all digits of the hands is seen in connective tissue diseases like scleroderma ( $\mathrm{Scl})$, systemic lupus erythematosus (SLE), and mixed connective tissue disease (MCTD), while a diffuse fusiform swelling that affects only one entire digit is observed in SpA, mostly in psoriatic arthritis (PsA) and reactive arthritis [12-14].

\section{Subluxation}

Subluxation is a prominent feature of patients with long-standing RA and SLE. The proximal phalanges sublux in an ulnar and palmar direction in relationship to the adjacent metacarpals. One, must distinguish the arthritis occurring in SLE from RA patients. The difference between them is that erosive changes are not seen in SLE patients. Subluxations do occur in OA, usually in a lateral direction deviating radially or ulnarly [12-14].

\section{Mineralization}

Mineralization is evaluated by observing the bones of the digits, especially the metacarpal shaft of the second or third digit where the $\mathrm{X}$-ray beam has a tangential direction. The sum of the cortices' thickness of the shaft should be equal to one-half of the width of the shaft in a normal bone. Osteopenia is not specific for a disease, as it can be observed in many conditions and in trauma. Regional, or periarticular osteopenia, is seen mostly in IA, especially in early RA around the PIPs and wrists, while 
diffuse osteopenia is seen in advanced RA and in SLE patients [12-14].

\section{Calcifications}

Calcifications may be seen in many conditions especially in patients with Scl, MCTD, dermatomyositis, but also in gout and CPPD disorders. They can be observed around the PIPs, DIPs, wrists, and in MCPs joints [12-14]. Each of these clinical entities may have characteristic distribution but most of the times it is difficult to distinguish them accurately.

\section{Bone Proliferation}

Two different kinds of bone formation must be distinguished: on one hand, new bone formation in the form of periostitis, enthesitis, and/or ankyloses, which is seen mostly in SpA and especially in PsA; on the other hand, a second form of bone production is a separate reparative response seen in OA and CPPD patients [12-14].

\section{Joint Space Narrowing}

There are two forms of joint space narrowing. A uniform joint space narrowing can be observed in all IA and it can be detected in the PIPs, MCPs, and the carpal bones, and a second form which consists of non-uniform joint space narrowing seen mainly in OA patients [12-14].

\section{Erosions}

Erosive changes are observed in all IA, metabolic, septic arthritis, and in erosive OA. However, the type, distribution, and location of the erosions within a specific joint is very important to distinguish and differentiate one disease from another. The erosions of an IA, especially in RA, occurs at the margins of the joints, which represent the "bare" areas of the bone, and are located within the joints between the edge of the articular cartilage and the attachment of the synovial membrane. On the other hand, erosive changes seen in erosive OA tend to occur in the central portion of the joint [12-14].

\section{Distribution of Radiographic Changes}

After the above description of the radiographic changes occurring in a specific joint, one must observe the distribution of these changes. This is why the type and location of these changes can differentiate one disease from another. More specifically, the DIP and PIP joints may be involved in OA, erosive OA, but also PsA patients. The PIPs and MCPs are affected from all forms of IA, but mostly RA, in a symmetrical manner, while in SpA the distribution is asymmetrical. The MCP joints are involved by all IA and by CPPD, while in gout a random distribution is seen. Regarding the distribution of the radiographic changes in the wrists (carpal bones), the examiner should pay attention to the radiocarpal compartment, the mid-carpal, the common carpometacarpal, and the first carpometacarpal compartment. The IA, and mainly RA, affect all the compartments of the carpal bones, while OA affects mostly the first carpometacarpal compartment. If OA-like changes are seen in other carpal compartments, then other conditions must be excluded such as metabolic disorders and trauma [12-14].

Regarding the radiographic findings seen in hands and wrists in RA patients, one must distinguish the changes of early RA and those seen in advanced and established disease. In early RA, symmetrical soft tissue swelling around the PIPs and wrists is evident. At the same sites, periarticular osteopenia, and the probability of marginal erosions affecting the PIPs, MCPs and carpal bones must be sought (Fig. 2). In established RA, there is a multitude of radiographic changes such as diffuse osteopenia, subluxations of the MCPs, uniform joint space narrowing, as well as large erosions affecting the PIPs, MCPs and carpal bones (Fig. 3) [14]. The presence of bone erosions using CR were once a criterion of the 1987 ACR classification criteria for RA [15]. In the 2010 ACR/EULAR classification criteria, the radiographic findings are not a criterion anymore [8], as it is considered a late finding of the disease. 


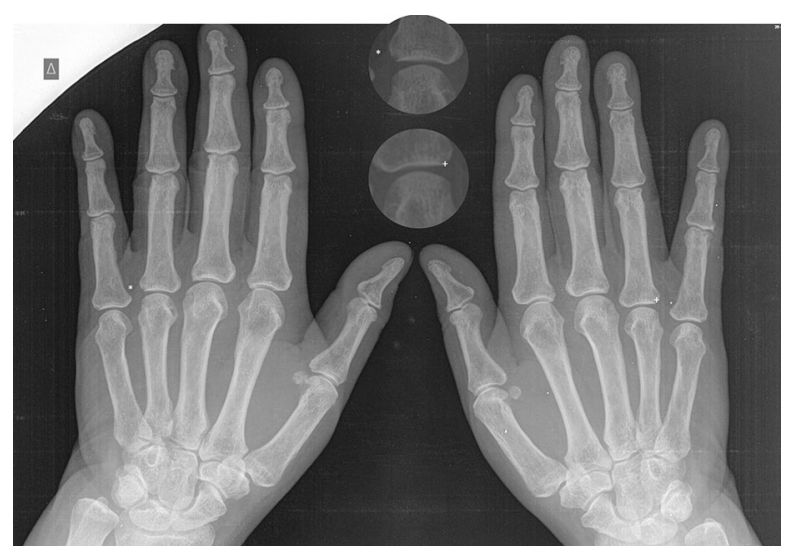

Fig. 2 Early RA: marginal erosions of the 4th right MCP $\left(^{*}\right)$ and the 4th left MCP in a 58-year-old female with a history of seropositive RA since 12 months. Also note the soft tissue swelling affecting mostly the 3rd and 4th PIPs of the right hand

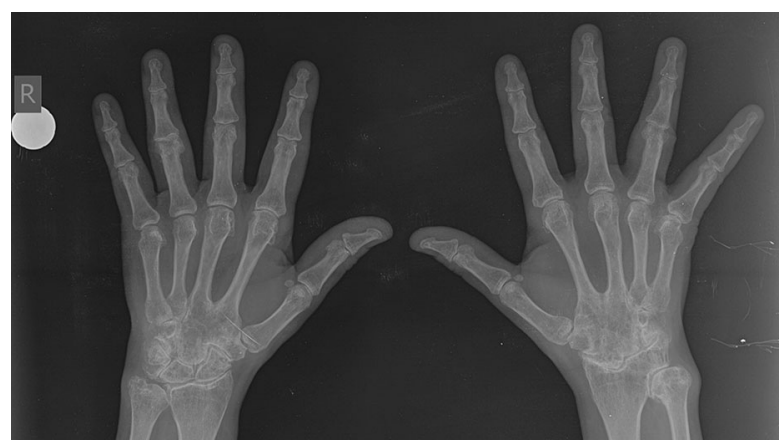

Fig. 3 Established RA: diffuse osteopenia, subluxations, joint space narrowing, bone erosions, and ankylosis affecting mostly the carpal and the carpometacarpal bones. Severe disease in a 50-year-old woman with a history of seropositive RA since the age of 31

\section{CALCIUM PYROPHOSPHATE DEHYDRATE CRYSTALS}

CPP crystals and CPPD are associated with a variety of clinical presentations, especially in the elderly, which are frequently asymptomatic. CPPD is a term that comprises many clinical disorders including CPP crystal arthritis. CPP crystal arthritis is an acute arthritis that is also called "pseudo gout" resembling acute gout arthritis. Usually, it is manifested as mono-, or oligo-arthritis, and in some instances as a polyarticular disease. Another form of CPPD is the chronic CPP crystal IA, called 'pseudo-RA', which may mimic RA presenting as a long-standing polyarticular disease. Chondrocalcinosis (CC) is the radiographic term of CPPD characterized by CPP crystal deposition in the cartilage. Finally, OA with CPPD is the most prevalent form of CPPD $[16,17]$. The definite diagnosis of CPPD requires the identification of CPP crystals in the synovial fluid [16, 17], although which is difficult to distinguish under a microscope. However, CR of the affected joints is a useful screening tool for CPPD diagnosis, as it can be supported by the radiographic finding of chondrocalcinosis, especially in the knees. On the other hand, CR detects only about $40 \%$ of clinically important CPPD [18]. Other imaging modalities like MSUS and/or dual-energy CT scan may be more appropriate and sensitive diagnostic techniques $[7,19,20]$. Laboratory tests are usually normal, but in cases with acute arthritis or chronic IA, the acute phase reactants can be elevated $[16,17]$. The radiographic findings of CPPD comprise the deposition of CPP crystals into fibrous and/or hyaline cartilage, in synovial capsules, tendons, and ligaments, which are visualized very well in CR. The most characteristic sites of CPP deposition include the knee, wrists, and pubic symphysis. Regarding the small joints of the hands and wrists affected by CPP crystal deposition, the most common sites involved are the carpal bones, especially the presence of crystal deposition in the triangular fibrocartilage and the hyaline cartilage between the lunate and triquetrum, followed by the involvement of MCP and PIP joints. In these locations, one must observe CPP crystal deposition in the joint capsule and, as a consequence of the chronic inflammation, there is a squaring of the bone ends, joint space narrowing, and hook-like osteophyte formation [16, 17] (Fig. 4). Several studies support the usefulness of performing radiographs to detect $\mathrm{CC}$ in uncommon sites [21].

Treatment of CCP depends on its clinical presentation. In the acute phase of the disease, intraarticular steroid injections, NSAIDs, and colchicine are required. In the chronic phase of CPPD, oral steroids, for a short period of time, NSAIDs and/or colchicine are used [17, 22, 23]. 


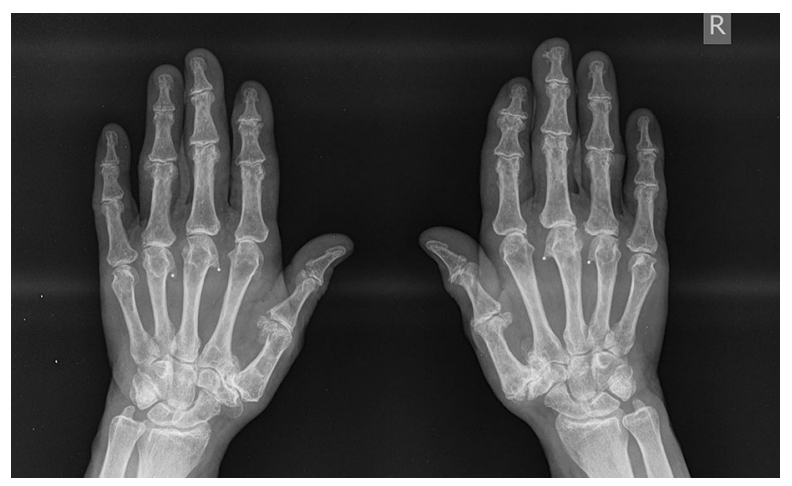

Fig. 4 CPPD disease: hook-like osteophyte formation affecting the MCPs $\left({ }^{*}\right)$ and scattered calcifications seen on CMCs and the PIPs in a 65-year-old male, with symmetrical polyarthritis affecting the small joints of the hand for the previous 5 years

Conventional synthetic (cs) disease-modifying anti-rheumatic drugs (DMARDs) like MTX and hydroxychloroquine (HCQ) have been used in some patients with controversial results [24-26]. Finally, Anakinra, an interleukin-1 (IL1) receptor antagonist has been used in severe cases [27].

\section{DISCUSSION}

Our patient had a chronic, symmetrical, polyarticular CPPD, affecting the small joints of the hands with the presence of high acute phase reactants, mimicking RA. Indeed, this patient satisfied the ACR/EULAR classification criteria for RA [8], but if hand and wrist X-rays were performed at the first visit, the diagnosis of a chronic form of CPPD would be obvious to the examiner. The patient responded very well to the treatment with prednisone and MTX, as was expected.

At this point, we would like to emphasize the importance of having performed hand and wrist radiographs in this patient at the first visit because this simple exam would provide enough information and would help the rheumatologist to have an accurate diagnosis. In cases where CR is not sufficient to provide all the necessary information for the underlying disease, then another imaging modality can be used to reach the correct diagnosis. This is very important because the prognosis and outcome of CPPD in comparison to RA is milder, with better outcomes, and no aggressive treatment. On the other hand, RA is a chronic inflammatory disease requiring continuous treatment with csDMARDs, and/or biologic (b) DMARDs with close monitoring and follow-up and worse prognosis. To this end, the EULAR recommendations for the management of early arthritis underline the importance to perform hand and wrist radiographs, along with other predictive factors (ESR, CRP, RF, and ACPA) for erosive disease $[28,29]$. The above parameters will guide rheumatologists in applying a different therapeutic strategy with cs, and/or bDMARDs $[30,31]$. Thus, in order to answer the questions that we addressed at the beginning of this manuscript, we can say that the assessment of joint pathology in patients with clinical manifestations of peripheral arthropathy should begin with CR. CR is the best imaging modality as an initial screening test in order to evaluate any changes occurring at the joint and bone level. It is an easy-to-perform and widely available technique, inexpensive, relatively safe, and provides immediate information in an established disease helping rheumatologists and physicians to differentiate one disease from another.

\section{ACKNOWLEDGEMENTS}

Funding. This study and the journal's Rapid Service Fee were funded by the authors.

Authorship. All named authors meet the International Committee of Medical Journal Editors (ICMJE) criteria for authorship for this article, take responsibility for the integrity of the word as a whole, and have given their approval for this version to be published.

Author Contributions. All authors have made substantial contributions to this manuscript and approved the final version fulfilling all the four criteria proposed be the ICMJE. EP: drafting; PVV: revision; AAD: conception of the work, revision. 
Disclosures. Alexandros A. Drosos, Eleftherios Pelechas, and Paraskevi V. Voulgari have nothing to disclose.

Compliance with Ethics Guidelines. This study was performed in accordance with the Helsinki Declaration of 1964 and its later amendments. Due to the nature of the manuscript and because no sensitive data of the patients are enclosed, there is no need to get permission from our university's ethics committee. All presented material is published after written consent of the patients although sensitive data and personal details are not included in the publication.

Open Access. This article is licensed under a Creative Commons Attribution-NonCommercial 4.0 International License, which permits any non-commercial use, sharing, adaptation, distribution and reproduction in any medium or format, as long as you give appropriate credit to the original author(s) and the source, provide a link to the Creative Commons licence, and indicate if changes were made. The images or other third party material in this article are included in the article's Creative Commons licence, unless indicated otherwise in a credit line to the material. If material is not included in the article's Creative Commons licence and your intended use is not permitted by statutory regulation or exceeds the permitted use, you will need to obtain permission directly from the copyright holder. To view a copy of this licence, visit http://creativecommons.org/licenses/by$\mathrm{nc} / 4.0 /$.

\section{REFERENCES}

1. Brower AC. Evaluation of the hand firm. In: Brower AC, editor. Arthritis in black and white, 2nd edn. Philadelphia: Sawnders; 1997. p. 33-67.

2. Jacobson JA, Girish G, Jiang Y, Resnick D. Radiographic evaluation of arthritis: inflammatory conditions. Radiology. 2008;248(2):378-89. https:// doi.org/10.1148/radiol.2482062110.

3. Wakefield RJ, Gibbon WW, Conaghan PG, O'Connor $\mathrm{P}, \mathrm{McG}$ anagle $\mathrm{D}$, Pease $\mathrm{C}$, et al. The value of sonography in the detection of bone erosions in patients with rheumatoid arthritis: a comparison with conventional radiography. Arthritis Rheum. 2000;43(12):2762-70. https://doi.org/10.1002/ 1529-0131(200012)43:12.

4. Grassi W, Fillippucci E, Farina A, Salaffi F, Cervini C. Ultrasonography in the evaluation of bone erosions. Ann Rheum Dis. 2001;60(2):98-103. https:// doi.org/10.1136/ard.60.2.98.

5. Ejbjerg BJ, Vestergaard A, Jacobsen S, Thomsen HS, Ostergaard M. The smallest detectable difference and sensitivity to change of magnetic resonance imaging and radiographic scoring of structural joint damage in rheumatoid arthritis finger, wrist, and toe joints: a comparison of the OMERACT rheumatoid arthritis magnetic resonance imaging score applied to different joint combinations and the Sharp/van der Hejde radiographic score. Arthritis Rheum. 2005;52:2300-6.

6. Filippou G, Pascart T, Iagnocco A. Utility of ultrasound and dual-energy CT in Crystal disease diagnosis and management. Curr Rheumatol Rep. 2020;22(5):15. https://doi.org/10.1007/s11926-0200890-1 (This study provides a thorough description about the diagnosis and management of crystal arthropathies using the ultrasound).

7. Jans L, De Kock I, Herregods N, Verstraete K, van den Bosch F, Carron P, et al. Dual-energy CT: a new imaging modality for bone marrow oedema in rheumatoid arthritis. Ann Rheum Dis. 2018;77(6): 958-60. https://doi.org/10.1136/annrheumdis2018-213152.

8. Aletaha D, Neogi T, Silman AJ, Funovits J, Felson DT, O'Bingham C, et al. 2010 Rheumatoid arthritis classification criteria: an American College of Rheumatology/European League Against Rheumatism collaborative initiative. Arthritis Rheum. 2010;62(9):2569-81. https://doi.org/10.1002/art. 27584.

9. Rudwaleit M, van der Heijde D, Landewe R, Listing J, Akkoc N, Brandt J, et al. The development of assessment of spondyloarthritis international society classification criteria for axial spondyloarthritis (part II): validation and final selection. Ann Rheum Dis. 2009;68(6):777-83. https://doi.org/10.1136/ ard.2009.108233.

10. Dasgupta B, Cimmino MA, Maradit-Kremers, Schmidt WA, Schirmer M, Salvarani C, et al. 2012 provisional classification criteria for polymyalgia rheumatica: a European League Against Rheumatism/American College of Rheumatology collaborative initiative. Ann Rheum Dis. 2012;71(4): 484-92. https://doi.org/10.1136/annrheumdis2011-200329. 
11. Neogi T, Jansen TL, Dalbeth N, Fransen J, Schumacher HR, Berendsen D, et al. 2015 gout classification criteria: an American College of Rheumatology/European League against Rheumatism collaborative initiative. Arthritis Rheumatol. 2015;67(10):2557-68. https://doi.org/10.1002/art. 39254 .

12. Salaffi F, Carotti M, di Carlo M. Conventional radiography in rheumatoid arthritis: new scientific insights and practical application. Int J Clin Exp Med. 2016;9(9):17012-27.

13. Liopis E, Kroon HM, Acosta J, Bloem JL. Conventional radiology in rheumatoid arthritis. Radiol Clin North Am. 2017;55(5):917-41. https://doi.org/ 10.1016/j.rcl.2017.04.002.

14. Drosos AA, Pelechas E, Voulgari PV. Conventional radiography of the hands and wrists in rheumatoid arthritis. What a rheumatologist should know and how to interpret the radiological findings. Rheumatol Int. 2019;39(8):1331-41. https://doi. org/10.1007/s00296-019-04326-4.

15. Arnett FC, Edworthy SM, Bloch DA, McShane DJ, Fries JF, Cooper NS, et al. The American Rheumatism Association 1987 revised criteria for the classification of rheumatoid arthritis. Arthritis Rheum. 1988;31(3):315-24. https://doi.org/10.1002/art. 1780310302 .

16. Zhang W, Doherty M, Bardin T, Barskova V, Guerne P-A, Jansen TL, et al. European League Against Rheumatism recommendations for calcium pyrophosphate deposition. Part I: terminology and diagnosis. Ann Rheum Dis. 2011;70(4):563-70. https://doi.org/10.1136/ard.2010.139105.

17. Rosenthal AK, Ryan LM. Calcium pyrophosphate deposition disease. N Engl J Med. 2016;374(26): 2575-84. https://doi.org/10.1056/NEJMra1511117.

18. Miksanek J, Rosenthal AK. Imaging of calcium pyrophosphate deposition disease. Curr Rheumatol Rep. 2015;17(3):20. https://doi.org/10.1007/ s11926-015-0496-1.

19. Filippou G, Filippucci E, Mandl P, Abhishek A. A critical review of the available evidence on the diagnosis and clinical features of CPPD: do we really need imaging? Clin Rheumatol. 2020. https://doi. org/10.1007/s10067-020-05516-3.

20. Filippou G, Scanu A, Adinolfi A, Toscano C, Gambera D, Largo $\mathrm{R}$, et al. Criterion validity of ultrasound in the identification of calcium pyrophosphate crystal deposits at the knee: an OMERACT ultrasound study. Ann Rheum Dis. 2021;80(2):261-7. https://doi.org/10.1136/ annrheumdis-2020-217998.
21. Parperis K, Carrera G, Baynes K, Mautz A, Dubois M, Cerniglia R, et al. The prevalence of chondrocalcinosis (CC) of the acromioclavicular (AC) joint on chest radiographs and correlation with calcium pyrophosphate dehydrate (CPPD) crystal deposition disease. Clin Rheumatol. 2013;32(9):1383-6. https://doi.org/10.1007/s10067-013-2255-X.

22. Zhang W, Doherty M, Pascual E, Barskova V, Guerne P-A, Jansen TL, et al. EULAR recommendations for calcium pyrophosphate deposition. Part II: management. Ann Rheum Dis. 2011;70(4):571-5. https://doi.org/10.1136/ard.2010.139360.

23. Terkeltaub RA, Furst DE, Bennett K, Kook KA, Crockett RS, Davis M. High versus low dosing of oral colchicine for early acute gout flare: twentyfour-hour outcome of the first multicenter, randomized, double-blind, placebo-controlled, parallel-group, dose-comparison colchicine study. Arthritis Rheum. 2010;62(4):1060-8. https://doi. org/10.1002/art.27327.

24. Chollet-Janin A, Finckh A, Dudler J, Guerne P-A. Methotrexate as an alternative therapy for chronic calcium pyrophosphate deposition disease: an exploratory analysis. Arthritis Rheum. 2007;56(2): 688-92. https://doi.org/10.1002/art.22389.

25. Finckh A, McCarthry M, Madigan A, van Linthoudt $D$, Weber M, Neto D, et al. Methotrexate in chronicrecurrent calcium pyrophosphate deposition disease: no significant effect in a randomized crossover trial. Arthritis Res Ther. 2014;16(5):458. https://doi. org/10.1186/s13075-014-0458-4.

26. Rothschild B, Yakubov LE. Prospective 6-month, double-blind trial of hydroxychloroquine treatment of CPPD. Compr Ther. 1997;23(5):327-31.

27. Ottaviani S, Brunier L, Sibilia J, Maurier F, Ardizzone M, Wendling D, et al. Efficacy of anakinra in calcium pyrophosphate crystal-induced arthritis: a report of 16 cases and review of the literature. Joint Bone Spine. 2013;80(2):178-82. https://doi.org/10. 1016/j.jbspin.2012.07.018.

28. Combe B, Landewe R, Lukas C, Bolosiu HD, Breedveld $\mathrm{F}$, Dougados $\mathrm{M}$, et al. EULAR recommendations for the management of early arthritis: report of a task force of the European Standing Committee for International Clinical Studies including Therapeutics (ESCISIT). Ann Rheum Dis. 2007;66(1): 34-45. https://doi.org/10.1136/ard.2005.044354.

29. van der Heijde D, Boonen A, Boers M, Kostense P, van der Linden $\mathrm{S}$. Reading radiographs in chronological order, in pairs or as single films has important implications for the discriminative power of rheumatoid arthritis clinical trials. Rheumatology (Oxford). 1999;38(12):1213-20. https://doi.org/10. 1093/rheumatology/38.12.1213. 
30. Smolen JS, Landewe RBM, Bijlsma JWJ, Burmester GR, Dougados M, Kerschbaumer A, et al. EULAR recommendations for the management of rheumatoid arthritis with synthetic and biological disease-modifying antirheumatic drugs: 2019 update. Ann Rheum Dis. 2020;79(6):685-99. https://doi.org/10.1136/annrheumdis-2019216655.
31. Drosos AA, Pelechas E, Voulgari PV. Treatment strategies are more important than drugs in the management of rheumatoid arthritis. Clin Rheumatol. 2020;39(4):1363-8. https://doi.org/10. 1007/s10067-020-05001-X. 